ADI WIDYA: Jurnal Pendidikan Dasar

FAKULTAS DHARMA ACARYA

INSTITUT HINDU DHARMA

NEGERI DENPASAR
Volume. 4, Nomor 2 Oktober 2019

ISSN: 2685-8312 (online)

ISSN: 2527-5445 (cetak

http://ejournal.ihdn.ac.id/index.php/AW

\title{
PENGEMBANGAN MEDIA PEMBELAJARAN BERBASIS TEKNOLOGI INFORMASI DALAM MENINGKATKAN MUTU PEMBELAJARAN PENDIDIKAN AGAMA HINDU ABAD 21
}

\author{
Oleh \\ Niluh Ari Kusumawati; Kadek Aria Prima Dewi PF \\ niluharikusumawati@gmail.com; primadewipf@gmail.com \\ Institut Hindu Dharma Negeri Denpasar, Indonesia
}

diterima 8 Agustus 2019, direvisi 17 September 2019, diterbitkan 1 Oktober 2019

\begin{abstract}
In this globalization era the role of science and technology covers various aspects of life, especially the world of Education. Education is an aspect of supporting the success of a nation. Hinduism Education is a subject that instills Hinduism. In learning Hinduism Education learning media becomes the main support of the learning process. Learning media as a channel for information and messages in learning. Information technology-based learning media is a demand in facing the challenges of 21 st century Education. 21st century education has four skills in learning communication (Communication), Collaboration (Collaboration), Critical Thingking and Problem Solving (Critical Thinking and problem solving) and Creativity and Innovation (Creativity and Innovation). With the guidance of the age development, the use of IT-based learning media in learning Hinduism Education will facilitate the transfer of knowledge in learning. The benefit of using IT-based learning media is to facilitate the interaction between teachers and students so that learning activities become effective and efficient The use of Information Technology-based learning media such as the internet, mobile phones, flash disks, etc. facilitates the transfer of knowledge in learning.
\end{abstract}

\section{Keyword: Media, Information Technology}

\section{PENDAHULUAN}

Perkembangan pengetahuan dan teknologi membawa pengaruh yang sangat besar terhadap berbagai bidang kehidupan.
Pendidikan memegang peranan penting dalam mengembangkan ilmu pengetahuan dan teknologi. Pendidikan abad 21 adalah Pendidikan yang tidak mengenal batas usia, gender, dan ruang dan waktu. Pendidikan 
yang baik dalah Pendidikan yang memanfaatkan kecanggihan ilmu pengetahuan dan teknologi agar mampu mencapai tujuannya secara efektif dan efesien. Menurut UNESCO empat pilar tujuan Pendidikan yaitu Learning to Know (Belajar untuk mengetahui), Learning to Do (Belajar untuk melakukan sesuatu, Learning to Be (Belajar untuk menjadi sesuatu, dan Learning to Live together (Belajar untuk hidup Bersama). Perkembangan ilmu pengetahuan dan teknologi berpengaruh pada media pembelajaran di sekolah-sekolah dan Lembaga-lembaga Pendidikan (Marcomm, 2018). Penggunaan teknologi informasi dalam proses pembelajaran di kelas sudah menjadi kebutuhan sekaligus tuntutan di era digital ini.

\section{Dalam pembelajaran}

Pendidikan Agama Hindu, media pembelajaran sebagai salah satu penunjang pembelajaran. Untuk meningkatkan efektivitas dan efisiensi pembelajaran Pendidikan Agama Hindu, perlu dikembangkan berbagai model pembelajaran yang kreatif dan inovatif (Suwantana, 2018). Hal ini agar pembelajaran semakin menarik dan tidak membosankan dan monoton. Peran media dalam proses pembelajaran menjadi sangat penting karena akan menjadikan proses pembelajaran menjadi bervariasi dan tidak membosankan. Proses pembelajaran merupakan proses komunikasi atau penyampaian informasi dari pendidik kepada peserta didik (Herlambang,
2018). Proses komunikasi yang terjadi berupa penyampaian materi pembelajaran yang dituangkan ke dalam simbol-simbol komunikasi baik verbal maupun non verbal. Daya tangkap siswa pada saat pembelajaran dipengaruhi oleh media pembelajaran yang diterapkan oleh guru.

Penelitian Eyler dan Giles menjelaskan bahwa keefektifan pembelajaran dipengaruhi oleh media yang digunakan guru. Dalam pembelajaran Pendidikan agama hindu peserta didik hanya dapat menyerap 5\% bahan pembelajaran apabila aktivitas ceramah (Dharmawacana) dilakukan oleh guru dalam proses pembelajaran (Transfer of knowledge) (Sanjaya, 2010). Media pembelajaran memegang peranan penting dalam pembelajaran sebagai penunjang dalam pembelajaran. Penerapan media pembelajaran berbasis TI dalam pembelajaran Pendidikan Agama Hindu memudahkan penyampain informasi dalam pembelajaran dan sesuai dengan tuntutan zaman.

\section{PEMBAHASAN}

\subsection{Media Pembelajaran}

Media adalah sesuatu yang dapat menyalurkan informasi dari sumber informasi ke pendengar informasi. Menurut Marshall McLuhan menjelaskan media adalah suatu eksistensi manusia yang memungkinkannya mempengaruhi orang lain yang tidak melakukan kontak langsung dengan dia (Hamalik, 2003). Media 
pembelajaran Pendidikan agama hindu mengalami perkembangan yang sangat pesat. Pada penerapan kurikulum 2013 media pembelajaran Pendidikan agama hindu menekankan pada media berbasis teknologi informasi. Media pembelajaran merupakan perangkat lunak (software) yang berupa informasi Pendidikan yang disajikan dengan menggunakan alat bantu (hardward) kepada pesaerta didik.

Menurut Bertz terdapat tiga unsur pokok media pembelajaran yaitu suara, visual dan gerak (Sanaky, 2009). Media pembelajaran visual dibedakan menjadi tiga yaitu gambar, garis ddan simbol yang dapat ditangkap oleh indra pengheliatan. Bertz juga mengklasifikasikan antara media siar dan media rekam sehingga dapat diklasifikasikan menjadi delapan media yaitu: (1) media cetak, (2) media audio, (3) media semi gerak, (4) media visual diam, (5) media audio visual gerak, (6) media audio visual diam, (7) media audio visual semi bergerak dan (8) media cetak. Dari penjelasan tersebut dapat disimpulkan bahwa jenis media yang dapat digunakan dalam pembelajaran Pendidikan agama hindu adalah sebagai berikut:

a. Media audio seperti radio, tape recorder dan telepon.

b. Media visual dibagi menjadi dua yaitu media visual diam dan media visual bergerak. Media visual diam merupakan media pembelajaran seperti buku, foto, majah, koran, poster, peta dan globe sedangkan media visual bergerak seperti film bisu.

c. Media audio-visual dibagi menjadi dua yaitu media audiovisual diam dan media audio visual bergerak. Media audiovisual diam seperti televisi diam, slide dan suara, film rangkai dan suara sedangkan media audiovisual bergerak seperti video, $\mathrm{CD}$, televisi, gambar dan suara.

d. Media serba seka dibagi menjadi enam yaitu (1) papan dan display seperti papan tulis, papan pengumuman dan majalah dinding, (2) media tiga dimensi seperti realia, sampel, artifact dan display, (3) media Teknik dramatisasi seperti drama, pantonim, bermain peran, pedalangan wayang dan simulasi, (4) sumber belajar pada masyarakat seperti kerja lapangan, studi wisata, dan perkemahan, (5) belajar terprogram dan (6) computer.

\subsection{Manfaat Media Pembelajaran}

\section{Materi} pembelajaran memiliki tingkat kesusahan yang berbeda- beda, media pembelajaran sangat diperlukan untuk memahami materi pembelajaran yang sulit. Media pembelajaran sebagai penunjang utama proses pembelajaran, sehingga dengan menggunakan media pembelajaran 
dapat mempermudah proses transfer informasi. Penggunaan media pembelajaran sebagai alat bantu dalam proses pembelajaran tidak dapat dipungkiri dengan semakin canggihnya ilmu pengetahuan dan teknologi (Sutirna, 2015). Guru sebagai pendidik mempunyai peran yang utama dalam proses pembelajaran. Guru menyadari bahwa tanpa media pembelajaran siswa akan sulit memahami materi yang diajarkan, maka dari itu dengan kecanggihan ilmu pengetahuan dan teknologi guru menggunakan media pembelajaran yang bervasiasi.

Secara umum manfaat media dalam proses pembelajaran adalah untuk mempermudah interaksi antara guru dan siswa sehingga kegiatan pembelajaran mejadi efektif dan efisien. Menurut Kemp dan Dayton terdapat beberapa manfaat media pembelajaran (Depdiknas, 2003) adalah sebagai berikut :
a) Penyampaian materi pembelajaran diseragamkan
b) Proses pembelajaran menjadi jelas dan menarik
c) Proses pembelajaran lebih interaktif
d) Efisiensi waktu dan tenaga dalam mengajar
e) Meningkatkan kualitas hasil belajar siswa
f) Proses belajar mengajar dapat dilakukan dimana saja dan kapan saja

g) Media menumbuhkan sikap positif siswa terhadap materi pembelajaran

h) Mengubah peran guru kea rah yang lebih positif

Selain beberapa manfaat media pembelajaran seperti diatas, terdapat manfaat praktis media pembelajaran. Beberapa manfaat praktis media pembelajaran adalah sebagai berikut:

a. Media membuat materi pembelajaran yang abstrak menjadi konkret

b. Media mengatasi masalah pembelajaran yang terkendala dengan ruang dan waktu

c. Media mengatasi keterbatasan indera manusia

d. Media dapat menyanikan objek pembelajaran yang bersifat langka

e. Materi pembelajaran yang disampaikan melalui media memperkuat daya serap dan daya ingat siswa terhadap materi pembelajaran yang disampaikan

Berdasarkan uraian di atas dapat disimpulkan bahwa manfaat media pembelajaran secara praktis adalah sebagai berikut :

a. Mengkonkretkan media pembelajaran yang bersifat abstrak menjadi visual sehingga mempermudah proses pembelajaran 
b. media pembelajaran yang bervariasi meningkatkan motivasi siswa dalam belajar.

c. Memungkinkan terjadinya interaksi antara siswa dan lingkungan,

d. Memberikan keseragaman dalam pengamatan sehingga daya tangkap setiap siswa berbeda- beda tergantung dari pengalamannya masingmasing.

e. Menyajikan materi pembelajaran secara konsiten sehingga dapat diulang dan dapat di simpan.

\subsection{Pengembangan Media}

\section{Pembelajaran Berbasis}

Teknologi Informasi (TI)

pada Pembelajaran

\section{Pendidikan Agama Hindu}

Di era digital ini penggunaan penggunaan media pembelajaran berbasis teknologi informasi menjadi sebuah kebutuhan. Penggunaan media pembelajaran berbasis teknologi informasi dalam pembelajaran Pendidikan Agama Hindu mempermudah dan mempercepat proses transfer materi pembelajaran kepada peserta didik. Teknologi elektronik yang dimanfaatkan dalam pembelajaran Pendidikan Agama Hindu adalah leptop/internet. Pemanfaatan jaringan komputer/internet memungkinkan peserta didik untuk melakukan komunikasi tertulis dan saling bertukar pikiran dalam proses pembelajaran (Helianthusonfri, 2018). Jaringan computer dirancang agar memudahkan pendidik untuk berkomunikasi dengan peserta didiknya. Pemanfaatan jaringan kompuputer dalam sistem Pendidikan jarak jauh disebut dengan Computer Conferencing System (CCF). Pada pembelajaran Pendidikan agama hindu site mini biasanya dilakukan dengan mengirimkan tugas memalui e-mail, hal ini semakin mempermudah dan mempercepat peserta didik dalam mengim tugasnya dan juga menghemat kertas karena tugas dikirim melalui e- mail. Beberapa media pembelajaran berbasis teknologi informasi (TI) dalam pembelajaran Pendidikan agama hindu adalah sebagai berikut:

\section{a. Internet}

Internet merupakan media pembelajaran berbasis TI, karena internet memunculkan modelmodel media pembelajaran yang bervariasi. Internet adalah jaringan komputer global yang mempermudah dan mempercepat akses informasi dan pengetahuan (materi pembelajaran) sehingga materi pembelajaran selalu dapat diperbaharui. Pengggunaan media internet dalam pembelajaran Pendidikan agama hindu seperti penggunaan e-learning dalam pembelajaran. Guru membuat 
google classroom agar mempermudah proses transfer materi pembelajaran. Pada umumnya guru menggunakan elearning sebagai media kolaborasi (collaboration) antara e-learning dan pembelajaran manual di kelas. Sehingga dengan penggunaan media internet dalam pembelajaran siswa tidak menjadi bosan karena guru selalu mengembangkan kreativitasnya dalam mengajar. Selain e-learning guru juga memanfaatkan google sebagai media mencari informasi dalam pembelajaran karena tidak semua materi pembelajaran terdapat pada buku. Pemanfaatan google sebagai media searching mempermudah proses pembelajaran sehingga pembelajaran dapat berjalan secara efektif.

\section{b. Mobile Phone}

Pembelajaran Pendidikan agama hindu berbasis teknologi informatika juga dapat dilakukan dengan penggunaan telpon sebagai media pembelajaran karena teknologi telpon seluler yang semakin canggih. Siswa dapat mengakses materi pembelajaran, mengikuti pembelajaran melalui telpon seluler. Seorang siswa biasanya mengerjakan tugas dengan searching di google, apabila ada tugas yang tidak dimengerti. Dan juga semakin pesat perkembangan teknologi informasi siswa juga dapat mengikuti pembelajaran dengan melakukan komunikasi (communication) melalui video call, biasanya fitur video call terdapat pada aplikasi whatshap, line, google dan lain sebagainya.

\section{c. Flash Disk}

Flash disk merupakan media pembelajaran berbasis TI, yang digunakan sebagai pilihan apabila jaringan internet tidak tersedia. Materi pembelajaran disimpan dalam flash disk kenudian dibuka dengan menggunakan computer/leptop. Pemanfaatan flash disk sebagai media pembelajaran meruoakan yang paling mudah dan murah.

Menurut I Ketut Gede Darma Putra terdapat dua komponen utama dalam pembelajaran berbasis TI, yaitu Learning Management System (LMS) dan learning Content (LC) (Putra, 2009).

\section{a. Learning Management System} (LMS)

LMS merupakan sistem computer yang diibaratkan sebagai staff administrasi yang mengatur penyelenggaraan proses belajar mengajar. LSM sebagai media pembelajaran memiliki fungsi yaitu: mengelola materi pembelajaran, registrasi dan persetujuan, merekan aktivitas belajar mengajar, melakukan evaluasi, media komunikasi dan pelaporan.

\section{b. Learning Content (LC)}

Learning content merupakan materi pembelajaran yang disajikan pada saat pembelajaran. Isi materi yang dibuat mempunyai kompetensi sesuai dengan mata pelajaran yang 
diajarkan.

Setelah

materi

pembelajaran dibuat kemudian akan dibuatkan versi elektroniknya. Penyajian materi pembelajaran dalam bentuk content harus memiliki daya tarik sehingga peserta didik memiliki minat untuk membaca. Learning content dapat diinovasi dengan memadukan unsur- unsur animasi, suara, video, dan lain sebagainya.

\section{SIMPULAN}

Media merupakan penunjang utama proses pembelajaran. Di era digital perkembangan media pembelajaran semakin maju. Penggunaan Teknoligi Informasi (TI) dalam pembelajaran menjadi tuntutan utama. Penggunaan media pembelajaran berbasis TI berupa internet, mobile phone, flash disk dan lain sebagainya. Dalam pembelajaran Pendidikan Agama Hindu media pembelajaran berbasis TI sebagai media yang paling efektif diterapkan dalam pembelajaran. Media pembelajaran berbasis TI membantu peserta didik dalam mencerna dan memahami materi pelajaran. Fungsi media dalam kegiatan pembelajaran sebagai alat praga dan media penyampaian informasi dalam pembelajaran.

\section{DAFTAR PUSTAKA}

Depdiknas. (2003). Media
$\begin{aligned} & \text { Pembelajaran. } \\ & \text { Depdiknas. }\end{aligned}$

Dewi, Kadek Aria Prima. "Pendidikan Berbasis Komunitas: Strategi Dalam Transformasi Nilai Di Sekolah Dasar."

Hamalik, O. (2003). Media Pendidikan. Bandung: PT Citra Aditya Bakti.
Helianthusonfri, J. (2018). Passive Income dari Google Adsense. Jakarta: PT Elex Media Komputindo.

Herlambang, Y. T. (2018). Pedagogik Telaal Kritis Ilmu Pendidikan Dalam Multiperspektif. Jakarta: Bumi Aksara.

Marcomm, M. (2018). Millennials. Jakarta: Fantasious X Loveable.

PF, K. and Partini, N. (2017). The Implementation of Yoga Teaching in Improving Elementary School Students' Learning Concentration.In 2nd International Conference on Sociology Education - Volume 2: ICSE, ISBN 978-989-758316-2, pages 149-155. DOI: 10.5220/0007106007890795

Putra, I. K. (2009). Pendidikan Berbasis Teknologi Informasi. Makalah ini disampaikan Pada Rakorda Disdikpora Bali - 10 Maret 2009.

Sanaky, H. A. (2009). Media Pembelajaran. Yogyakarta: Safaria Insania Press.

Sanjaya, P. (2010). Filsafat Pendidikan Hindu. Singaraja: Paramita Surabaya.

Siswadi, G. A., \& Wiguna, I. M. A. (2019). Integrasi Pendidikan Agama Hindu Dalam Pembelajaran Bahasa Sanskerta Pada Yayasan Dvīpāntara Samiskrtam. Jurnal Penelitian Agama Hindu, 3(1), 57-64.

Sutirna. (2015). Landasan Pendidikan Teori dan Praktek. Bandung: Refika Aditama.

Suwantana, G. (2018). Tantangan Hindu Di Indonesia Gagasan dan Solusi Melenial Masa Kini. Denpasar: PT Japa Widya Duta 